\title{
PARENIALISME SEBAGAI LANDASAN DALAM PEMBELAJARAN BAHASA INDONESIA
}

\author{
Asih Riyanti \\ Pendidikan Bahasa Indonesia, Universitas Borneo Tarakan, Indonesia \\ E-mail: asihriyanti17@gmail.com
}

\begin{abstract}
Abstrak
Parenialisme lahir sebagai reaksi dan solusi terhadap pembelajaran progresif karena adanya keadaan krisis kebudayaan dalam kehidupan yang modern. Filsafat progresivisme menekankan perubahan menuju hal baru, sedangkan filsafat parenialisme mengedepankan jalan mundur ke masa lampau, yakni mengembalikan nilai dan prinsip yang telah menjadi pandangan hidup yang kukuh pada zaman dahulu. Pengembalian atas nilai dan prinsip hidup tersebut dapat ditempuh melalui pendidikan, yakni dalam pembelajaran bahasa Indonesia. Setiap manusia memiliki bahasa sebagai alat komunikasi antarsesama. Melalui bahasa, maka seseorang dapat menyampaikan ide, gagasan, atau mengetahui informasi yang dibutuhkan. Pembelajaran bahasa Indonesia diajarkan pada semua jenjang pendidikan baik sekolah dasar hingga perguruan tinggi. Pembelajaran bahasa Indonesia dianggap wajib dan penting di dunia pendidikan karena sebagai bahasa persatuan, bahasa kebangsaan, dan sebagai jati diri bangsa Indonesia. Dalam proses pembalajaran, bahasa Indonesia bukan hanya pencapaian pengetahuan terkait bahasa untuk tujuan akademik, tetapi tetap tidak mengesampingkan nilai dan prinsip hidup dalam konsep pendidikan yang secara integral dalam payung dari disiplin ilmu pendidikan, yakni salah satunya filsafat parenialisme. Pada pembelajaran bahasa Indonesia, parenialisme sebagai landasan dalam teori, praktik, proses pelaksaan pembelajaran sampai pada tahap evaluasi pembelajaran. Belajar bahasa Indonesia berarti pula memenuhi fungsi praktik filosofi baik ilmu, etika berbahasa, sosial, politik serta seni relevansinya terhadap budaya.
\end{abstract}

Kata Kunci: Parenialisme; Pembelajaran Bahasa Indonesia

\begin{abstract}
Parennialism was born as a reaction and solution to progressive learning because of the state of cultural crisis in modern life. The philosophy of progressivism emphasizes change towards new things, while the philosophy of parentalism puts forward a way back to the past, that is, returning values and principles that had become a solid view of life in ancient times. Returns on these values and life principles can be achieved through education, namely in learning Indonesian. Every human being has language as a means of communication between people. Through language, someone can convey ideas, ideas, or find out the information needed. Indonesian learning is taught at all levels of education, from elementary school to university level. Learning Indonesian is considered compulsory and important in the world of education because it is the language of unity, national language, and as the identity of the Indonesian people. In the process of learning Indonesian language is not only the achievement of knowledge related to language for academic purposes, but it does not rule out the values and principles of life in the concept of education which is integrally within the umbrella of the discipline of educational science, one of which is the philosophy of parentalism. In learning Indonesian parentalism as a foundation in theory, practice, the process of implementing learning to the evaluation stage of learning. Learning Indonesian also means fulfilling the functions of philosophical practices both science, language ethics, social, politics and the arts of their relevance to culture.
\end{abstract}

Keywords: Parentalism; Indonesian Language Learning 


\section{Pendahuluan}

Keadaan dunia sekarang mengalami kekacauan akibat dari pesatnya perubahan yang terjadi akibat arus globalisasi. Hal ini dapat berakibat buruk apabila manusia tidak dapat memilih dan menyaring hal-hal yang masuk di kehidupan. Hal itu berakibat akan terjadi krisis berbagai dimensi kehidupan khususnya pada ranah pendidikan. Oleh sebab itu, tujuan pendikan harus ditentukan secara jelas dan perilaku pendidik yang stabil. Banyak faktor yang menentukan keberhasilan pendidikan, misalnya faktor landasan pendidikan, tujuan, dan arah pendidikan yang diselaraskan dengan nilai filsafat baik secara ontologis, epistemologis, dan aksiologis.

Era industri saat ini menjadikan negara mengalami kegundahan karena apapun serba cepat dan mengedepankan hal-hal baru. Tampaknya ini lupa akan pentingnya masa lampau, yakni budaya yang bahwasanya dimiliki oleh setiap negara. Hal itulah yang kemudian kaum parenialis berupaya melawan kegagalan dan tragedi dalam zaman modern dengan mundur. Artinya, kembali kepada kepercayaan aksiomatis yang terus secara handal, baik tentang hakikat realita, pengetahuan, maupun nilai yang telah memberi dasar bagi abad sebelumnya. Tegasnya, filsafat parenialisme lebih menekankan pada filsafat tradisional dan filsafat modern yang telah banyak menurunkan derajat pada rasionalitas dan sains (Saitya, 2018).

Pekembangan era indusutri saat ini mendesak aliran parenialis, yakni berharap manusia saat ini dapat tetap dan selalu memahami ide dan cita-cita filsafatnya bukan hanya sebagai suatu asa. Hal itu dapat dilakukan melalui pendidikan salah satunya melalui proses pembelajaran bahasa Indonesia.

Setip hari manusia selalu berinteraksi dengan manusia yang lain dengan bahasa. Manusia dapat mengetahuai informasi dan menuangkan gagasan atau idenya melalui bahasa. Oleh sebab itu, seseorang harus mampu menguasai unsur bahasa baik diksi, struktur, kosa kata, ejaan, dan sebagainya. Todd (2000) menyatakan bahasa merupakan seperangkat tanda yang digunakan untuk berkomunikasi dengan sesama. Terdapat tanda dan simbol yang sudah dikonvensikan sebagai perangkat tanda untuk berkomunikasi, yang disepakati sebagai bahasa yang memiliki referen yang jelas.

Brown (2007) berpendapat bahwa bahasa ialah seperangkat simbol mana suka yang berarti antara penanda dan petanda tidak terdapat hubungan wajib yang semua hanya didasarkan pada kesepakatan antara penutur bahasa di masyarakat tersebut. Oleh karena itu, penggunaan bahasa sangat berdekatan dengan budaya yang melekat pada bahasa itu. Artinya, setiap bahasa mempunyai budaya dan melekat dengan bahasa itu.

Pada hakikatnya pembelajaran bahasa Indonesia bukanlah semata-mata mempelajari untuk megejar pemahaman materi ke depan, tetapi mampu mengintegrasikan budaya dan seni di dalamnya. Pembelajaran bahasa dengan berbagai materi pembelajaran dapat dikembangkan dan memasukkan nilai-nilai religius dan budaya. Dengan demikian, tujuan pembelajan bahasa Indonesia menjadi lebih sempurna.

Pembelajaran bahasa Indonesia sering dianggap remeh oleh para pebelajarnya karena merasa hanya tujuan akan demikianlah yang menjadi orientasinya. Sebenarnya permasalahan yang sebenarnya ialah belum optimalya dalam menyelaraskan antara bahasa dengan budaya. Hal ini perlu adanya integrasi mata pelajaran atau mata kuliah bahasa Indonesia dengan mata kuliah lain yang bermuatan budaya. Itulah sebabnya seorang pengajar atau pendidik perlu mengetahui landasan filosofi pendidikan bahasa agar dalam menentukan proses dan tujuan pembelajaran bahasa tidak over laping serta tetap memperoleh nilai-nilai budaya dalam rangka mewujudkan kemajuan bangsa dan membangun sumber daya manusia yang berkualitas. Dengan demikian, landasan filosofi sebagai dasar pembelajaran bahasa Indonesia dapat dicapai dalam memperkokoh nilai-nilai universal pada landasan filosofi yang ada.

\section{Metode}

Metode yang digunakan dalam artikel ini adalah study kepustakaan. Artikel ini disusun dengan menelaah buku-buku, artikel imiah sejenis, dan referensi-referensi yang berkaitan dengan parenialisme dalam pembelajaran bahasa Indonesia. Selain itu, telaah terhadap penelitian sejenis juga dilakukan untuk mendapat simpulan yang valid. 


\section{Hasil dan Pembahasan}

\section{Parenialisme dalam Pembelajaran Bahasa Indonesia}

Era industri sekarang sangat mengandalkan rasionalitas positivistis yang memandang kebenaran dalam konteks yang serba terukur, taramati, dan teruji, yang realitas sebagai suatu materi. Ketidakmampuan manusia melihat pengetahuan yang sebenarnya dapat muncul apabila berpikir logis sudah diabaikan. Hal ini perlu diatasi dengan berlandaskan pada sebuah filsafat pendidikan.

Parenialiasme merupakan suatu aliran filsafat pendidikan yang percaya dan mengedepankan adanya nilai, norma yang bersifat kekal di dunia ini. Nilai dan norma terus tumbuh dan berkembang di masayarakat yang sifatnya mengikat untuk menjadi pegangan dalam mempertahankan keutuhan masyarakat (Nuryamin, 2019). Parenialis berarti segala sesuatu yang ada dalam sejarang manusia. Hal ini dapat memberikan solusi bagi masalah kehidupan di masyarakat dengan menggunakan dan menerapkan dalam menghadapi alam yang modern yang penuh dengan masalah kehidupan (Pratte, 1971). Filsafat arenialis menjelaskan pesoalanpersoalan yang bersifat hakikat dari seluruh ajaran agama dan tradisi manusia. Tradisi berkaitan dengan masalah cinta dan sikap, merupakan sumber hukum masyarakat, menerapkan prinsip dalam masyarakat, dan memberikan berbagai warna pada IPTEKS.

Pada abad ke dua puluh, parenialisme ini lahir sebagai suatu reaksi terhadap progresif. Aliran parenilisme tidak sependapat dengan kaum progresif karena selalu menekankan ada perubahan kepada hal baru. Kaum parenialis melihat dunia saat ini terjadi ketidakpastian dan ketidaktreraturan, khususnya dalam hal moral, intelektual, dan sosiokultural. Bagi kaum parenialisme, adanya hal tersebut diperlukan usaha guna mengamankan dan mengembalikan kekacauan tersebut. Salah satunya ialah melalui pendidikan.

Secara etimologis, parenialisme berasal dari bahasa latin, yakni kata perennial dengan imbuhan -isme yang berarti kekal, abadi, satu selamanya (Hidayat, 2003). Kaum parenialis ini menekankan pentingnya budi, nalar, dan sangat mengapresiasi budaya masa lampau. Berkaitan dengan pendidikan, aliran filsafat memandang bahwa pendidian dapat digunakan sebagai jalan untuk kembali ke belakanag dari kebudayaan masa lampau. Habsari (2003) menyatakan parenialis memiliki pandangan yang bertolak dari modernisasi yang menurutnya telah menjauh dari tradisi dan terlalu mengedepankan logika dan rasio dari pada pengetahuan lainnya, serta memandang materi ialah segalanya. Perlu diingat bahwa esensi manusia ada pada rasionalitas, maka faktor intelektual memerlukan perhatian khusus manusia sebagai manusia. Esensi dari pendidikan yang general selalu bekenaan dengan kehidupan intelektualitas.

Tokoh parenialisme ialah Plato (427-347 SM), Aristoteles (384-322 SM), Thomas Aquinas. Bagi Plato pendidikan ialah memebina manusia menjadi satu atas asas normatif dan melaksanakan dalam semua segi kehidupan. Sementara itu, Aristoteles menyadari manusia hakikatnya berada dalam kondisi materi dan sosial, sedangkan Thomas Aquinas menyebutkan bahwa pengetahuan didapatkan sebagai persentuhan dunia luar dan oleh akal budi yang kemudian menjadi sebuah pengetauan. Adler sebagai pendukung parenialisme mengemuakakan bahwa manusia ialah mahkluk rasional yang hakikatnya senantiasa seperti di sepanjag sejarahnya, maka manusia memiliki gambaran yang tetap dalam program pendidikan dengan tidak mengikutkan peradapan dan masa lampau (Kneller, 1971).

Konsep dasar pendangan aliran parenialis (Gandhi, 2013), yakni: (1) dari ontologisnya bahwa manusia secara esensi sebagai makhluk berpikir, sementara aksionnya manusia sebagai orang yang menyukai terhadap seni dan secara substansi manusia sebagai individu yang khas dan universal; (2) secara etimologis parenialnisme berlandaskan pada trusth, self evidence, dan reasoning. Hubungan pengetahuan dan realita semesta sangatlah penting. Dengan kata lain kedudukan filsafat lebih tinggi dari pada ilmu pengetahuan; (3) pandangan aksologi yakni berpegang pada nilai dan norma yang sifatnya abadi. Parenialisme ini mengambil analogi realita sosial budaya manusia. Konsep dasar pandangan tersbut di atas dapat digunakan sebagai acuan dalam belajar. Bagi kaum parenialis belajar merupakan tempat dalam mempersiapkan, menata, berpikir, dan merencanakan masa depan untuk tujuan moral dan intelektual sebagi hasil dan proses belajar. Tujuan yang dimaksud tentu sebagai bekal hidup yang dapat berguna memenuhi fungsi baik ilmu seni, etika, sosial, dan politik (practical philosophy). Belajar dapat dilakukan dengan bimbingn guru, dengan kata lain melakukan proses membelajarkan siswa yakni pada ranah pendidikan.

Pendidikan memandang parenialisme sebagai jalan untuk mengembalikan keadaan saat ini. Ketidakteraturan dunia saat ini, menjadikan terombang-ambingnya manusia dalam menjalani 
kehidupan. Pembelajaran pada dunia pendidikan dapat berlandaskan pada filsafat parenialisme yang menganggap sebagai aliran yang memiliki keinginan kembali ke masa lampau. Anwar (2015) menyatakan sikap dari kaum parenial kembali masa lampau bukan berarti bernostalgia dan mengenangnya tetapi lebih pada membina kembali keyakinan yang kuat terhadap nilai-nilai asasi masa lampau yang tentu diperlukan untuk kehidupan. Dalam hal ini berarti pembelajaran bahasa Indonesia dapat berpegang teguh berlandaskan pada aliran parenialis guna membina, mengembangkan, dan meningkatkan kembali keyakinan atas nilai-nilai asasi masa lampau untuk menghadapi kehidupan manusia sekarang dan masa mendatang.

Pendidikan bagi parenialis hendakanya berorientasi pada potensi psikologis masyarakat, mengembangkan potensi akalnya, supaya menjadi manusia cerdas dan mau berpikir sehingga dapat mewujudkan pemenuhan kelas sosial dalam masyarakat tertentu (Jalaludin, 1997). Manusia sebagai mahklusk sosial dan makhluk yang khas memiliki keunikan masing-masing dalam kehidupannya harus diajarkan pengetahuan dan pemahaman tentang nilai dan norma yang berlaku di masyarakat. Hal ini agar tidak menyimpang dari aturan di masyaraakat. Sadulloh (2015) mengemukakan bahwa pendidikan bukan merupakan peniruan dari hidup. Sekolah tidak pernah menjadi suasana kehidupan nyata. Bagi anak merupakan aturan yang artifisial di mana dirinya berkenalan dengan hasil yang terbaik dari wawasan sosial budaya.

Parenialis dipandang penting dalam pembelajaran bahasa. Pembelajaran bahasa Indonesia sebagai mata pelajaran wajib di sekolah-sekolah seyogyanya diajarkan hal-hal bukan hanya dari segi bahasa saja tetapi harus memiliki pandangan yang bertolak pada modernisasi. Parenialisme ini memandang bahwa untuk mengembalikan keadaan yang kacau. Apabila tidak ada jalan lain, maka dapat menempuh jalan yakni memusatkan perhatian kepada kebudayaan silam yang dianggap ideal.

Dalam pembelajaran dengan berlandaskan parenialisme, proses pembelajaran cenderung berpusat pada siswa. Materi ajar mengarah ada kepentingan siswa dalam menumbuhkembangkan potensi berpikri, sedangkan dalam pendekatan dan metode menggunakan diskusi, problem solving, dan penelitian. Guru harus bersiap membimbing dan mengarahkan siswa. Guru bertugas membangkitkan potensi yang dimiliki oleh sisiwa yang masih tersembunyi sehingga menjadi nyata, bukan membentuk atau memberi kemampuan kepada siswa. Itu sebabnya guru sebagai pendidik yang mempersiapkan siswa menuju arah kematangan intelektualnya.

Guru berperan sebagai motivator, mediator, dan fasilitator yang harus mampu melakukan proses penyerapan ilmu yang diajarkan kepada siswanya. Pendidikan bahasa dalam parenialisme cenderung bersifat religius dan lebih bertujuan aturan dogmatis, serta mengedepankan budaya pada masa lampau. Pada aliran parenialisme ini guru sebagai fasislitator untuk membangkitkan potensi siswa yang belum nampak agar menjadi nyata. Siswa dalam pembelajaran ialah sebagai subyek dan inti pelaksana pendidikan.

Penguasaan keterampilan berbahasa menjadi kebutuhan penting untuk dikuasai. Berbagai bahasa dan budaya yang dimiliki bangsa Indonesia memegang peran sebagai kontrol sosial. Ketika tidak ada kontrol sosial maka nilai agama, nilai kesantunan, nilai kerukunan, dan keamanan tidak lagi dijunjung tinggi. Oleh sebab itu, dibutuhkan penanaman nilai agama dan nilai budaya, sehigga muncul filsafat pendidikan bahasa yang sangat penting sebagai landasan pembelajaran bahasa. Fungsi filsafat parenialisme sebagai landasan pembelajaran bahasa Indonesia, yakni agar dalam pendidikan bahasa lebih terarah sesuai dengan nilai luhur bangsa Indonesia.

Muhmidayeli (2013) berpendapat tugas peserta didik /siswa dalam aliran ini mempelajari berbagai karya dalam literatur filsafat, sejarah, dan sains. Namun dalam hal ini, siswa perlu meraih subyek dasar sepetri bahasa, matematika, pengetahuan alam, dan seni guna mengembangkan pikirannya agar mampu berpikir rasional yang kuat dalam menghadapi tantangan di masyarakat. Dalam kurikulum, akan tampak materi yang mengarah pada kebutuhan dan kepentingan siswa dalam menumbuhkembangkan potensi siswa dalam berpikir kreatif. Adapun untuk yakni metode pembelajaran menggunakan kebebasan berpikir individu, diskusi, dan pemecahan masalah dalam penelitian dan penemuan.

Dalam kegiatan pembelajaran bahasa Indoensia dapat dilakukan oleh guru untuk siswa mengapresiasi karya-karya agung dalam literatur yang menyangkut sejarah, filsafat, seni, begitu juga dengan politik dan ekonomi. Keuntungan yang didapat mempelajari buku masa lampau, yakni segala masalah siswa dapat dicari jawabannya dengan menggunakan prinsip dan kebijakan yang telah dimiliki manusia sehingga mampu berpikir dengan bijak. 
Pembelajaran bahasa dapat berperan serta mengontrol sosial sehingga siswa akan terbina norma dan nilai melalui pembelajaran bahasa yang ditanamkan melalui topik, tema, dan sub topik yang langsung dapat mengangkat nilai budaya. Habsari (2003) mengemukakan metode pembelajaran yang digunakan para kaum parenialis ialah membaca dan diskusi tentang karya dalam rangka mendisiplinkan pikiran siswa.

Kaitannya dengan hal di atas, maka guru dapat memberikan tema dan topik dengan memasukkan unsur kebudayaan dan nlai moral. Sebagi contoh kegiatannya ialah keterampilan membaca yang harus dikuasi siswa, tentu guru harus dapat memilih bahan ajar yang dapat dijadikan sebagai praktik membaca siswa. Memilih bahan ajar yang berbasis budaya dan nilai pada masa lampau dapat menjadi jembatan siswa mengenal dan menumbuhkan jiwanya untuk berpikir dan kembali pada nilai dan budaya masa lalu yang tidak hanya mengandalkan pengetahuan. Guru harus memiliki aktualisasian pengetahuan yang sempurna.

Jika dikaitkan dengan kurikulum, maka aliran parenialis memandang kurikulum pendidikan sifatnya harus subject centerd, yakni berpusat pada materi pelajaran. Materi pelajaran seharusnya bersifat universal, kekal, dan terarah kepada pembentukan rasionalitas manusia. Dalam hal kurikulum, yang terpenting ialah isi (content) mata pelajaran yang benar dan tepat. Oleh karena itu, guru memegang peran utama dalam pembelajaran.

Berkaitan dengan penilaian hasil belajar panerinialisme maka mengikuti teori pendidikan klasik, yakni bukan hanya manghafal tetapi tetap memiliki nilai dan sikap postif. Diperlukan bentuk penilaian yang mengakomodasi mengenai karakteristik dan keberagaman kebudayaan siswa. Penilaian hasil belajr parenialisme adalah: (1) menggunakan ujian dan tes kognitif dan psikomotorik; (2) perolehan nilai melalui tes dapat digunakan memecahkan masslaah; (3) penggunaan bentuk evaluasi disesuaikan dengan tujuan mata pelajaran; bidang studi humaniora bisanya dalam bentuk tes uraian; (4) adanya tes dilakukan untuk mengukur penguasan materi bagi siswa; dan (5) siswa yang berrhasil ialah yang menguasai ilmu keseluruhan atau sebagaian beasr isi pendidikan.

Dengan demikian, dapat dikatakan bahwa parenialisme sebagai pengetahuan yang selalu ada yang bersifat universal. Hasil dalam proses pembelajaran maka pengetahuan yang dimiliki siswa bukan hanya kognitif tetapi nilai dan prinsip hidup yang berlaku di masyarakat. Oleh sebab itu, jalan untuk mencapainya yakni melatih intelek dan disiplin mental. Sehingga sisiwa memperoleh dan merealisisasikan kebenaran yang abadi.

\section{Simpulan dan Saran}

Setiap manusia hakikatnya sama bahwa sebagai makhluk rasional. Berlandaskan filsafat parenialisme di atas maka pendidikan diapandang sebagai jalan kembali atau untuk mengembalikan manuisia saat ini dalam budaya yang ideal. Pendidikan sebagai dasar meningkatkan kualitas manusia yang mengacu pada kerangka nilai dan moral dan universal. Pendidikan tidak dapat dilepaskan dari nilai yang bersumber pada kekuatan budaya dan nilai serta norma di masyarakat. Parenialisme sebagai landasan dalam pembelajaran bahasa perlu dipahamai benar-benar oleh para pendidik dan pengambil kebijakan pendidikan. Hal ini bermanfaat demi kemajuan pendidikan. Esensi parenialisme, yakni menerapkan nilai dan norma yang sifatnya kekal atau dikatakan sebagai jalan mundur kepada budaya masa lampau. Filsafat parenialisme sebagai landasan pembelajaran bahasa Indonesia mengedepankan (1) Teori dasar, yakni melalui pendidikan bahasa Indonesia senantiasa melihat kedisiplinan siswa dalam melakukan proses pembelajaran yang mengaitkan teori belajar bahasa dengan nilai dan prinsip hidup di masyarakat secara integral. Hal ini dapat dilakukan dengan kurikulum bahasa yang disesuaikan dnegan lingkungan, karekteristik pebelajar, metode yang berpusat pada siswa, dan materi-materi dengan topik-topik yang menyesuaikan diri dengan nilai, moral, dan budaya sekitar dengan memperhatikan hakikat kebenaran (2) Proses pembelajaran, penilaian, dan evaluasi dilakukan oleh guru bukan hanya pada hasil tetapi pada proses pembelajaran yang bukan hanya berorientasi pada tujuan kognitif, tetapi harus mengedepankan nilai dan prinsip hidup untuk memenuhi kebutuhan sebagai fitrahnya manusia. (3) Pendidik sebagai orang yang belajar, yakni menyadari bahwa dirinya sebagai motivator, mediator, dan kolaborator antara materi ajar dengan siswa dalam menghadapi dan menanggapi tuntutan sosial. Melalui langkah demikian, maka manusia dapat terbentuk sikap dan kepribadiannya selain budaya sebelumnya. Pembelajaran bahasa Indonesia terdapat di semua jenjang sekolah perlu diperhatikan dalam kebermanfaatannya, yakni mampu mengembangkan seorang individu. 


\section{Daftar Pustaka}

Anwar, Muhammad. 2015. Filsafat Pendidikan. Jakarta: Prenada Media Group.

Brown, D. 2007. Principles of Language and Teaching (fifth Edition)). San Fransisco State Univerrsity: Pearson Longman.

Gandhi HW, Teguh Wangs. (2013) Filsafat Pendidikan: Mahzab-Mhzab Filsafat Pendidikan. Yogyakartal Ar-Ruzz Media.

Jalaludin \& bdullah Idi. (2997). Filsafat Pendidikan. Jakarta: Gaya Media Pratama.

Hidayat, Komarudin dan Muhammad Wahyuni Nafis. (2003). Agama Masa Depan Perspektif Filsafat Parennial. Jakarta: Gramedia Pustaka Utama.

Kneller, George F. (1971). Introduction to The Philosophy of Education. New York: Jonh Weley \& Sons, Inc.

Habsari, Novi Triana. (2003). Implementasi Parenialisme dalam Pembelajaran Sejarah. Jurnal Agstya. Vol 03.No.1 pp149-159.

Muhmidayeli. (2013). Filsafat Pendidikan. Cet II. Bandung: PT Refika Aditama.

Nuryamin. (2019). Implementasi Filsafat Parenial dalam Pembelajaran. Jurnal Aqidah-Ta. Vol V.No.1.pp 49-61.

Pratte, Richard. 1971. Cotemporary Theories of Education. Scranton: Educational Publisher.

Sadulloh, Uyoh. 2015. Pengantar Filsafat Pendidikan. Bandung: Alfabeta.

Saitya, Ida Bagus Subrahmanian. (2018). Filsafat Sebagai Upaya mencegah Radikalisme di Indonesia. Journal IImu Sosial dan IImu Politik. VI 9, No 1 pp 22-27.

Tood, Loretto. (2000). Introduction to Linguistic. Singapure: York Press. 